\title{
Order-Dependent Coincidence Detection in Cerebellar Purkinje Neurons at the Inositol Trisphosphate Receptor
}

\author{
Dmitry V. Sarkisov and Samuel S.-H. Wang \\ Department of Molecular Biology and Princeton Neuroscience Institute, Princeton University, Princeton, New Jersey 08544
}

\begin{abstract}
Associative long-term depression (LTD) at cerebellar parallel fiber-Purkinje cell synapses is sensitive to the temporal order in which the parallel fiber is coactivated with the climbing fiber input, but how order sensitivity is achieved is unknown. Here we show that the cerebellar inositol-1,4,5-trisphosphate $\left(\mathrm{IP}_{3}\right)$ receptor, whose activation is required for LTD induction, is sensitive in situ to the order of presentation of its coagonists, $\mathrm{IP}_{3}$ and cytoplasmic calcium. By focally photolyzing a novel caged $\mathrm{IP}_{3}$ compound in dendritic spines, we find that pairing $\mathrm{IP}_{3}$ with climbing fiber-mediated calcium entry leads to a large calcium release transient if the climbing fiber is activated up to $100 \mathrm{~ms}$ before or up to $500 \mathrm{~ms}$ after $\mathrm{IP}_{3}$ uncaging. This asymmetric timing window for coactivation follows the kinetics of calcium removal and $\mathrm{IP}_{3}$ unbinding from the receptor and is not limited by $\mathrm{IP}_{3}$ metabolism. $\mathrm{IP}_{3}$ receptor binding thus acts as an eligibility trace that can drive temporal order-dependent calcium release and LTD induction in Purkinje cells and event order-dependent sensory plasticity in the whole animal.
\end{abstract}

Key words: coincidence detection; inositol trisphosphate receptor; $\mathrm{IP}_{3}$; calcium channels; LTD (long-term depression); plasticity; Purkinje neurons

\section{Introduction}

In associative synaptic plasticity, a key quality of any synaptic coincidence detection mechanism is whether it can detect the temporal order of the arrival of triggering events. At most synapses, the sign and amount of plasticity depend on the order in which presynaptic activity and postsynaptic spike activity occur (Abbott and Nelson, 2000). At cerebellar parallel fiber (PF)-Purkinje cell (PC) synapses, such order dependence has been proposed to underlie the learning of a conditional sensory stimulus when it specifically precedes an unconditional stimulus (Gormezano et al., 1983; Raymond and Lisberger, 1998).

A proposed substrate for sensory learning is associative longterm depression (LTD) of the PF-PC synapse, in which PF synapses are weakened when they are coactivated with the powerful climbing fiber (CF) input to the PC. The induction of PF-LTD requires cytosolic calcium elevation (Sakurai, 1990), which leads to depression of PF responses by modulation and internalization of postsynaptic AMPA-type glutamate receptor via a protein kinase C (PKC)-dependent pathway (Bear and Linden, 2001; Ito, 2002; Koekkoek et al., 2003). Purkinje cells strongly express the inositol 1,4,5-trisphosphate $\left(\mathrm{IP}_{3}\right)$ receptor (Furuichi et al., 1989; Inoue et al., 1998), an endoplasmic reticulum calcium release

\footnotetext{
Received April 17, 2007; revised 0ct. 28, 2007; accepted Nov. 1, 2007

This work was supported by the Burroughs Wellcome Fund (D.V.S.), the Whitehall Foundation, the Rita Allen Foundation, and National Institutes of Health Grant NS045193 (S.S.-H.W). S.S.-H.W. is a W. M. Keck Foundation Distinguished Young Investigator. We thank C. D. Brody, E. F. Civillico, and G. M. Wittenberg for comments on this manuscript and S. E. Gelber and J. W. Walker for synthesis of double-caged IP $\mathrm{P}_{3}$.

Correspondence should be addressed to Samuel Wang, Department of Molecular Biology and Princeton Institute for Neuroscience, Lewis Thomas Laboratory, Washington Road, Princeton, NJ 08544 . E-mail: sswang@princeton.edu.

DOI:10.1523/JNEUROSCI.1729-07.2008

Copyright $\odot 2008$ Society for Neuroscience $\quad 0270-6474 / 08 / 280133-10 \$ 15.00 / 0$
}

channel that is required for LTD induction (Khodakhah and Armstrong, 1997). At PF-PC synapses, $\mathrm{IP}_{3}$ is produced via the synaptic activation of metabotropic glutamate receptors, which are activated by bursting (Takechi et al., 1998) or spatially clustered (Marcaggi and Attwell, 2005) PF activity. PF-induced calcium release is enhanced by calcium entry from the CF-activated dendritic action potential, which acts as a coagonist at $\mathrm{IP}_{3}$ receptors (Iino, 1990; Bezprozvanny et al., 1991; Finch et al., 1991; Nakamura et al., 1999), and in this way can detect the coincidence of PF and CF inputs (Berridge, 1993; Wang et al., 2000).

At the cellular level, large amounts of $\mathrm{IP}_{3}$-dependent spine calcium release occur in response to bursts of PF activity that precede CF activation, a condition that induces PF-LTD (Schreurs et al., 1996; Wang et al., 2000); PF-LTD is also induced by the pairing of dendritic $\mathrm{IP}_{3}$ uncaging with somatic depolarization (Khodakhah and Armstrong, 1997). Biochemical studies have demonstrated that in hepatocytes, $\mathrm{IP}_{3}$ receptor-dependent calcium release is sensitive to the order of presentation of $\mathrm{IP}_{3}$ and calcium on a subsecond time scale (Marchant and Taylor, 1997). Metabotropic receptor-dependent calcium release is enhanced by action potentials that come after synaptic activation by hundreds of milliseconds in hippocampal pyramidal neurons (Nakamura et al., 1999) and in cerebellar Purkinje cells (Wang et al., 2000). However, the role of $\mathrm{IP}_{3}$ receptor properties in setting timing-dependent coincidence detection has not been probed directly. We tested the coincidence detector properties of $\mathrm{IP}_{3}$ receptors in cerebellar Purkinje neurons, by photolyzing doublecaged $\mathrm{IP}_{3}$ to optically activate $\mathrm{IP}_{3}$ receptors directly without triggering other metabotropic receptor-dependent $\mathrm{PF}$-activated biochemical pathways. Responses were quantified by monitoring calcium changes to $\mathrm{IP}_{3}$ and dendritic action potentials using twophoton laser-scanning microscopy. 


\section{Materials and Methods}

Brain slices. Sagittal 300- $\mu$ m-thick cerebellar brain slices were cut from 17- to 21-d-old rats or 2- to 3-month-old calbindin knock-out mice (strain B6.129-Calb1 ${ }^{\text {tm1Mpin }} / \mathrm{J}$; The Jackson Laboratories, Bar Harbor, $\mathrm{ME}$ ) in ice-cold artificial CSF (ACSF) containing (in mM) $126 \mathrm{NaCl}, 3$ $\mathrm{KCl}, 1 \mathrm{NaH}_{2} \mathrm{PO}_{4}, 20$ D-glucose, $25 \mathrm{NaHCO}_{3}, 2 \mathrm{CaCl}_{2}$, and $1 \mathrm{MgCl}_{2}$ and saturated with $95 \% \mathrm{O}_{2} / 5 \% \mathrm{CO}_{2}$. Slices were preincubated at $34^{\circ} \mathrm{C}$ for 40-60 min and then kept at room temperature. For recording, slices were transferred to an immersion-type recording chamber perfused at $2-4 \mathrm{ml} / \mathrm{min}$ with ACSF solution saturated with $95 \% \mathrm{O}_{2} / 5 \% \mathrm{CO}_{2}$. Purkinje cells were visually patched with borosilicate patch recording electrodes (4-7 M $\Omega$ ) filled with a solution containing (in $\mathrm{mM}, \mathrm{pH}$ to 7.30 with $\mathrm{KOH}) 133$ methanesulfonic acid, $7.4 \mathrm{KCl}, 0.3 \mathrm{MgCl}_{2}, 3 \mathrm{Na}_{2} \mathrm{ATP}, 0.3$ $\mathrm{Na}_{3} \mathrm{GTP}$, and 0.3 fluo-5F (Invitrogen, Carlsbad, CA). Solutions also contained $300 \mu \mathrm{M}$ single-caged $\mathrm{IP}_{3}$ (Invitrogen), $100 \mu \mathrm{M}$ 4,5-double-caged $\mathrm{IP}_{3}$ (homemade), or caged gPIP 2 (Calbiochem, San Diego, CA). Additional drugs used were thapsigargin (Tocris Bioscience, Ellisville, $\mathrm{MO}$ ) added to the bath or ruthenium red (Sigma-Aldrich, St. Louis, MO) or heparin (sodium salt, low molecular weight from porcine intestinal mucosa, lot \#057K1403, Sigma-Aldrich) added to the patch electrode solution. The same type of heparin from Calbiochem and heparin sodium salt from Sigma-Aldrich (catalog \#H4784) were ineffective in blocking calcium release. Electrophysiological signals were acquired with an Axopatch 200B amplifier and Clampex 8.0 software (Axon Instruments, Foster City, CA). After whole-cell break-in, cells were held in current clamp mode for at least $40 \mathrm{~min}$ to allow diffusion of the dye and caged compound to distal dendrites and spines. Holding currents at $-65 \mathrm{mV}$ were -50 to $-400 \mathrm{pA}$ and series resistances were $20-30 \mathrm{M} \Omega$. Series resistance was monitored periodically and compensated by balancing the bridge. The CF input was activated with an ACSF-filled electrode placed in the granule layer, positioned to evoke reliable responses with 10-30 V bipolar pulses. Between trials, the CF input was stimulated every $10 \mathrm{~s}$ to maintain calcium in the endoplasmic reticulum. Antibodies against calbindin (Sigma-Aldrich) were used to test for calbindin expression by Western blot analysis. For experiments in which coincidence detection was tested near the potassium reversal potential, the potassium concentration was increased to $18 \mathrm{~mm}$.

Two-photon microscopy and focal uncaging. Two-photon fluorescence imaging was done using a custom-built microscope controlled by CfNT software (M. Müller, Max Planck Institute for Medical Research, Heidelberg, Germany). Light (830 nm excitation) from a Mira 900 Ti:sapphire laser (Coherent, Santa Clara, CA) was focused onto the brain slice by $63 \times, 0.9$ numerical aperture water-immersion objective (Carl Zeiss, Oberkochen, Germany). The setup for focal uncaging was as previously described (Sarkisov and Wang, 2006). Briefly, the output of a UV laser (DPSS Laser, San Jose, CA) was attenuated by a polarizing beam splitter, widened by a $5 \times$ beam expander (CVI Laser, Albuquerque, NM) to fill the back aperture of the objective, and merged with the excitation beam using a dichroic mirror (Omega Optical, Brattleboro, VT). To compensate for the focal plane shift between uncaging and excitation light, the uncaging beam was slightly converged by adjusting the beam expander.

Data analysis. Calcium transients were recorded in line scan mode (128 pixels, $2 \mathrm{~ms}$ per line) and postprocessed using IgorPro (WaveMetrics, Lake Oswego, OR). To measure total calcium response, unfiltered $\Delta F / F_{0}$ traces were integrated for $200 \mathrm{~ms}$ starting at the time of the second stimulus. To measure peaks of the $\Delta F / F_{0}$ transients, traces were convolved with a Hanning window of width 5 samples. For all figures, a Hanning window of width 3 samples was applied except for Figure 3, A and $B$, which shows unfiltered data. The response latency was defined by finding the postphotolysis $50 \mathrm{~ms}$ interval with the steepest linearly fitted slope and defining the fit's intercept with the baseline as the end of the latent period.

To estimate the changes in units of calcium concentration, resting calcium was estimated using as the indicator dye 50-200 $\mu \mathrm{M}$ fluo-4, whose affinity $\left(K_{D}=540 \mathrm{nM}\right)$ and dynamic range $\left[R_{f}=100\right.$; interpolated from Woodruff et al. (2002) for $1 \mathrm{mM} \mathrm{Mg}^{2+}, \mathrm{pH} 7.2,25^{\circ} \mathrm{C}$ ] allow convenient quantification of both resting and maximal fluorescence. Resting calcium was estimated by saturating the indicator (Maravall et al., 2000) by repeated stimulation of the climbing fiber input. Calibration according to formula 7 in Maravall et al. (2000) gave an average resting calcium concentration of $80 \mathrm{nM}$. Calcium concentrations using fluo-5F were calculated assuming $K_{D}=1.0 \pm 0.2 \mu \mathrm{M}$ and $R_{f}=220$. Assuming an uncertainty of $20 \%$ in resting calcium because of variability among cells and potential lack of saturation by climbing fiber activation, uncertainties in resting calcium and $K_{D}$ can be combined using standard error propagation methods to give an overall near-rest calibration factor, $2.5 \pm 0.7 \mathrm{nM}$ change in nominal free calcium per $1 \%$ change in $\Delta F / F_{0}$. Calibrated values of calcium concentration are shown as a second vertical axis in Figure $1 D$.

All statistics are reported as mean \pm SEM unless otherwise indicated. Significance tests are one-tailed unless otherwise indicated.

\section{Results}

We filled PCs in cerebellar brain slices with $100 \mu \mathrm{M}$ double-caged $\mathrm{IP}_{3}$ and $300 \mu \mathrm{M}$ of the fluorescent calcium indicator fluo-5F $\left(K_{\mathrm{D}}\right.$ $=1.0 \pm 0.2 \mu \mathrm{M})$. Our choice of a moderate-affinity calcium indicator allowed us to detect micromolar calcium changes with a high signal-to-noise ratio without overwhelming the calciumbinding buffer capacity of the PC (Kosaka et al., 1993), as would occur with a higher-affinity indicator. Double-caged $\mathrm{IP}_{3}$ was used because at high concentrations, single-caged $\mathrm{IP}_{3}$ blocks calcium release in spines and spiny dendrites (Sarkisov et al., 2007). Fluorescence measurements and uncaging were done using a custom-built two-photon laser-scanning microscope integrated with a focal submicrometer photolysis system (Fig. 1A,B) (Sarkisov and Wang, 2006). UV flash energy was adjusted so that flash-evoked signals (Fig. $1 C$, middle trace) were smaller than CF-evoked signals, as has been observed for PF-evoked calcium release signals (Wang et al., 2000). Flash-evoked signals in spines reached a median $\Delta F / F_{0}=127 \%$, interquartile range $70-178 \%$; and in dendrites, a median $\Delta F / F_{0}=113 \%$, interquartile range $56-150 \%$. CF-evoked signals peaked at $\Delta F / F_{0}$ values of $270-$ $430 \%$ in spines and $110-240 \%$ in dendrites (interquartile ranges), corresponding to peak calculated calcium concentrations of $0.4-0.7 \mu \mathrm{M}$ and $0.2-0.4 \mu \mathrm{M}$, respectively, consistent with prior measurements (Miyakawa et al., 1992; Brenowitz and Regehr, 2005).

In contrast to the separately presented stimuli, coincident presentation of $\mathrm{IP}_{3}$ and CF activation produced spine calcium signals in the supramicromolar range. Pairing of $\mathrm{IP}_{3}$ uncaging in spines or spiny dendrites (Fig. $1 B$ ) with a CF stimulus $400 \mathrm{~ms}$ later triggered calcium signals (Fig. $1 C$, red bottom trace) that were substantially larger than either the CF-alone (top trace) or $\mathrm{IP}_{3}$ alone (middle trace) signals or their linear sum (black bottom trace). In experiments in which $\mathrm{IP}_{3}$ uncaging preceded CF stimulation by $50-200 \mathrm{~ms}$, calcium signals were enhanced in 28 of 30 trials (different from chance, $p<0.001$, Fisher exact test) in 17 spines (peak of coincidence signal $\Delta F / F_{0}=560 \pm 40 \%$, mean \pm SEM; greater than peak of linear sum $\Delta F / F_{0}=360 \pm 30 \%, p<$ 0.05 ) and in 42 of 43 trials (different from chance, $p<10^{-6}$ ) in 20 dendrites (peak of coincidence signal $\Delta F / F_{0}=320 \pm 20 \%$; greater than peak of linear sum $\Delta F / F_{0}=220 \pm 20 \%, p<0.05$ ) (Fig. 1D). The interquartile ranges of these peak coincidence signals (Fig. 1D) were 390-710\% in spines, corresponding to calculated calcium concentrations of $0.6-1.8 \mu \mathrm{M}$ (mean $1.1 \mu \mathrm{M})$; and $210-440 \%$ in dendrites, corresponding to calculated calcium concentrations of $0.3-0.7 \mu \mathrm{M}$ (mean $0.5 \mu \mathrm{M}$ ).

We quantified the total enhancement of responses in two ways designed to reduce noise and to emphasize the contribution from prolonged calcium release, which is distributed over hundreds of milliseconds (Sarkisov et al., 2007) (Fig. 2A). First, to report the relative amount of boosting we defined a supralinearity index, $S$, 
A
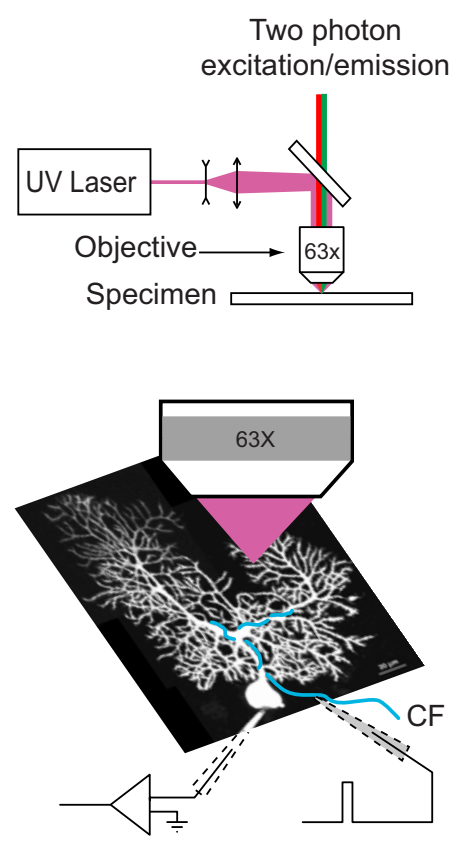

B

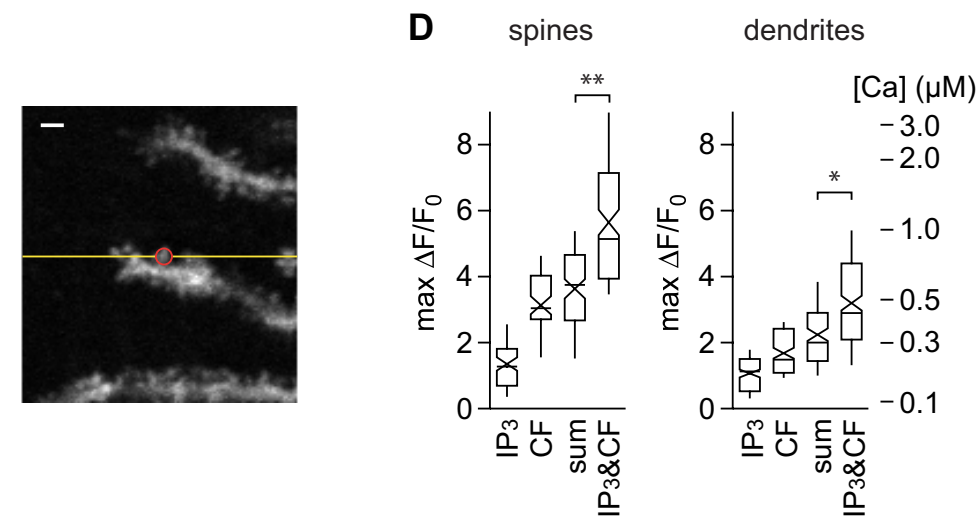

Figure 1. Supralinear calcium transients. $\boldsymbol{A}$, Experimental setup. Purkinje cells were filled with calcium-sensitive dye and double-caged IP ${ }_{3}$ for photolysis by UV light. The CF was activated by a stimulus electrode, and calcium signals were detected using a custom-built two-photon microscope. $\boldsymbol{B}$, Spiny dendrites of a Purkinje cell. The yellow line indicates the position of a line scan, and the red circle indicates an uncaging spot over a spine. Scale bar, $1 \mu \mathrm{m}$. C, Calcium transients in the spine from $\boldsymbol{B}$. Uncaging $\mathbb{P}_{3}$ (middle trace) $400 \mathrm{~ms}$ before (F stimulation (top trace) leads to enhanced calcium response (red trace) larger than the linear sum of separately evoked transients (black bottom trace). $\boldsymbol{D}$, Box plots of peaks of responses to $\mathbb{P}_{3}$ uncaging, $(F$ stimulation, their linear sum, and coincident stimulation with $\mathbb{P}_{3}$ preceding $C F$ by $50-200$ ms. $^{*} p<0.05$ and ${ }^{* *} p<0.01$, one-tailed Student's $t$ tests.

which was calculated as the ratio of the integrated coincidence calcium response to the linear sum of the separate $\mathrm{IP}_{3}$ and CF responses. Second, we used the CF-alone signal as a standard benchmark to calculate an index of the supralinear component, $C$, defined as the excess of the coincidence signal over the linear sum divided by the size of the CF-alone signal. An enhancing effect is indicated by values of $S>1$ and $C>0$. Like the peakbased measurements, both of these indices also showed enhancement of calcium signal in spines $(S=1.55 \pm 0.08, S>1, p<$ 0.005; $C=0.79 \pm 0.10, C>0, p<0.001)$ and dendrites $(S=$ $1.49 \pm 0.04,>1, p<0.001 ; C=0.93 \pm 0.08,>0, p<0.001)$. Enhancement was even seen close to the soma in the primary dendrite $(S=1.37 \pm 0.06,>1, p<0.05 ; C=1.07 \pm 0.16,>0, p<$ $0.001 ; n=11$ trials in 2 cells; $\mathrm{IP}_{3}$-to-CF interval of $150-200 \mathrm{~ms}$ ).

To test whether $\mathrm{IP}_{3}-\mathrm{CF}$ coincidence detection was sensitive to order, the presentation timing was reversed so that $\mathrm{IP}_{3}$ came after the CF stimulus by $250 \mathrm{~ms}$. Under this condition, signals showed little supralinearity (Fig. 2B). Overall, supralinearity was dependent on the time interval between $\mathrm{IP}_{3}$ uncaging and $\mathrm{CF}$ stimulus both in spines (Fig. 2C) and in spiny dendrites (Fig. 2D). Synergy in calcium release depended on the order and interval $\Delta t$ of stimulus presentation in spines (peak average $C$ at $\Delta t=+135 \mathrm{~ms}$, where a positive sign of $\Delta t$ denotes $\mathrm{IP}_{3}$ before CF; Gaussian fit centered at $\Delta t=+200 \pm 30 \mathrm{~ms}$ with half-maximal width $510 \pm 80 \mathrm{~ms}$; center different from zero, $p<0.001$ by twotailed test) and in dendritic shafts (peak average $C$ at $\Delta t=+105 \mathrm{~ms}$; fit centered at $\Delta t=+140 \pm 25 \mathrm{~ms}$, half-maximal width $540 \pm 60 \mathrm{~ms}$; center different from zero, $p<0.001$ by two-tailed test).

The true degree of supralinearity of calcium release is greater than implied by analysis of fluorescence changes because peak levels of calcium can saturate the indicator. Although indicator saturation would not affect the basic phenomenon of an asymmetric timing window, the true width of the timing window might be narrower than shown in Figure $2 C$ as a result of underreporting of the largest calcium signals. We repeated the supralinearity calculations using calibrated calcium values. Although the calculated supralinearity was substantially higher (values of $C$ up to 6) (see supplemental Fig. 1, available at www.jneurosci.org as supplemental material), the parameters of the timingdependence curve (Gaussian fit for $C$ centered at $\Delta t=225 \pm 40 \mathrm{~ms}$ with halfmaximal width $560 \pm 100 \mathrm{~ms}$ ) were indistinguishable from parameters fitted to fluorescence data. Thus, analysis of fluorescence accurately reflects the timingdetection properties of $\mathrm{IP}_{3}$ receptors without need for calibration to units of calcium concentration.

To determine the timing conditions at which half-maximal enhancement occurred, we made line fits to data in the intervals $\Delta t=[-300$, $+100]$ and $[+100,+1000]$ ms. Half-maximal values of $C$ occurred in spines at $\Delta t=-75 \pm 30 \mathrm{~ms}$ from exact coincidence when CF was activated first, and at $\Delta t=+530 \pm 100 \mathrm{~ms}$ when $\mathrm{IP}_{3}$ was presented first. In dendrites, half-maximal values of $C$ occurred at $\Delta t=-110 \pm 30 \mathrm{~ms}$ and $+470 \pm 80 \mathrm{~ms}$. Similar timing windows were measured using measures based on supralinearity $S$ (Fig. 2C,D, left) (for spines, half-maximal enhancement at $\Delta t=$ $-90 \pm 40 \mathrm{~ms}$ and $+560 \pm 120 \mathrm{~ms}$, and for dendrites at $\Delta t=$ $-170 \pm 60 \mathrm{~ms}$ and $+520 \pm 120 \mathrm{~ms}$ ).

To test whether order dependence was dependent on how long the signal was integrated, the supralinearity $S$ was recalculated for integration windows different from the standard duration used, $200 \mathrm{~ms}$. Pairwise comparisons were made between positive intervals $\Delta t=(+150$ to $+250 \mathrm{~ms})$ and negative intervals $(-150$ to $-250 \mathrm{~ms})$. $S$ was different between positive and nega- 
A

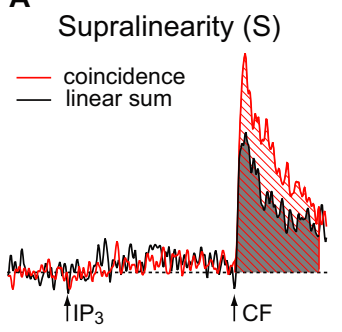

B

CF before $\mathrm{IP}_{3}$

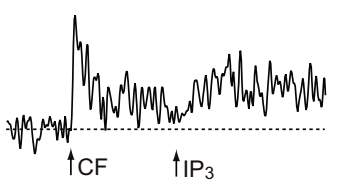

C
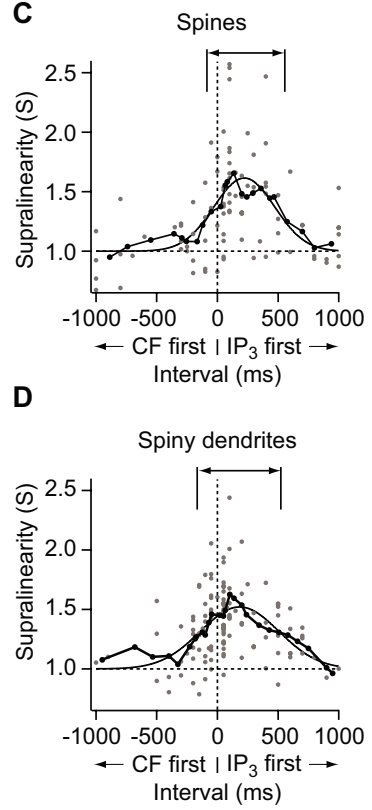

E

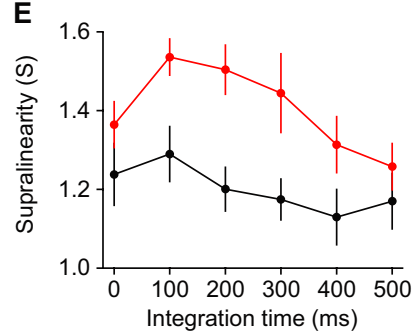

Figure 2. Timing dependence of $\mathrm{IP}_{3}$ receptor-mediated coincidence signals. $A$, Two indices used to quantify enhancement of calcium transients: $S$ (left), ratio of coincidence signal to the linear sum of independently evoked transients, C (right), ratio of enhancement to the CF-evoked response. B, Order dependence of supralinear transients. An example showing a total calcium transient in a spine in response to $C$ Factivation followed by $\mathrm{IP}_{3}$ uncaging $250 \mathrm{~ms}$ later (left) that is smaller than a response to $\mathbb{I P}_{3}$ uncaging followed by $\mathrm{CF}$ stimulus (right). $C, D$, Total supralinear enhancement of the calcium response as a function of interval between $C F$ stimulation and $\mathbb{I}_{3}$ uncaging in spines $(\boldsymbol{C})$ and spiny dendrites of Purkinje cells $(\boldsymbol{D})$. Thick black curves represent a moving average of all measurements made at a timing interval and at the intervals immediately adjacent; the intervals were averaged as well. The thin black curves are Gaussian fits. $E$, Supralinearity index $S$ for a variety of signal integration times, ranging from peak value only $(0 \mathrm{~ms})$ to integration times of $100-500 \mathrm{~ms}$. Red points indicate $\mathbb{P}_{3}$-CF intervals of +150 to $+250 \mathrm{~ms}$; black points indicate $\mathbb{P}_{3}-$ CF intervals of -150 to $-250 \mathrm{~ms}$. tive intervals for a range of temporal fluorescence signal integration windows (Fig. 2E).

To determine the source of calcium in coincidence signals, we applied three blockers of calcium release from the endoplasmic reticulum (ER): thapsigargin, heparin, and ruthenium red. After application of 2-4 $\mu \mathrm{M}$ thapsigargin, which inhibits ER calcium reuptake pumps and thus depletes calcium stores, $\mathrm{IP}_{3}$ uncaging did not lead to measurable calcium elevation $\left(\Delta F / F_{0}=-4 \pm 2 \%\right.$ in dendrites at $100 \mathrm{~ms}$ after uncaging, $n=34$ trials at 38 locations in 2 cells). Thapsigargin led to no measurable supralinear component when $\mathrm{IP}_{3}$ was uncaged before $\mathrm{CF}$ activation $(C=0.03 \pm$ $0.02, n=38$ trials at 12 locations in 2 cells; $\Delta t=+150-200 \mathrm{~ms}$ ). Inclusion of the $\mathrm{IP}_{3}$ receptor blocker heparin $(150 \mu \mathrm{g} / \mathrm{ml})$ blocked both flash-evoked calcium release $\left(\Delta F / F_{0}=-3 \pm 2 \%\right.$ in dendrites at $100 \mathrm{~ms}$ after uncaging, $n=45$ trials at 11 locations in 2 cells) and supralinearity $(C=0.01 \pm 0.04 ; n=29$ trials in 11 locations, 2 cells; $\Delta t=+200 \mathrm{~ms})$. When the recording pipette solution included ruthenium red $(50 \mu \mathrm{M})$ to block ryanodine receptors, the other type of calcium release channel in the ER membrane, the supralinear component was still present $(C=$ $0.73 \pm 0.07, n=32$ trials at 11 locations in 3 cells; $\Delta t=+150 \mathrm{~ms}$ ). Together, these experiments show that $\mathrm{IP}_{3}-\mathrm{CF}$ supralinearity requires release from calcium stores via $\mathrm{IP}_{3}$ receptors. Finally, supralinear calcium transients were also detected in experiments performed at higher temperatures $(C=0.97 \pm 0.13, n=22$ trials at 5 locations in 1 cell; $T=32^{\circ} \mathrm{C}, \Delta t=-200$ to $+200 \mathrm{~ms}$ ).

CF activity might enhance calcium release not only by the direct action of calcium on the $\mathrm{IP}_{3}$ receptor, but also by enhancing $\mathrm{IP}_{3}$ formation via CF-released glutamate acting on metabotropic receptors (Dzubay and Otis, 2002) or calcium-dependent activation of phospholipase C (Grobler and Hurley, 1998). Enzyme-mediated effects on calcium release would be expected to begin after a delay of tens of milliseconds (Takechi et al., 1998). We found that the earliest observable supralinearity (Fig. $3 A$ ) occurred almost immediately after presentation of the CF stimulus (see also Fig. 1C). The coincidence signal began to exceed the linear sum (Fig. 3B, bottom trace) (average of 14 trials in spiny dendrites, $\mathrm{CF} 50 \mathrm{~ms}$ after $\mathrm{IP}_{3}$ uncaging) starting $6 \mathrm{~ms}$ after the $\mathrm{CF}$ stimulus. The difference reached 2 SD above zero by $12 \mathrm{~ms}$ after the CF stimulus, near the peak time of the CF-alone signal (Miyakawa et al., 1992). The fact that calcium release begins to be enhanced so quickly, even before the end of calcium entry, supports the hypothesis that $\mathrm{CF}$ enhances $\mathrm{IP}_{3}$-dependent calcium release by direct action of calcium on $\mathrm{IP}_{3}$ receptors (Finch et al., 1991).

To test whether $\mathrm{IP}_{3}$ must already be present for CF-mediated calcium entry to enhance calcium release, $\mathrm{CF}$ activation was given before $\mathrm{IP}_{3}$ uncaging (Fig. $3 C$ ). Under this condition, a prominent feature of the coincidence signal was its divergence from the linear sum in the form of a shortening of the latency to calcium rise from $31 \pm 5 \mathrm{~ms}$ after uncaging of $\mathrm{IP}_{3}$ to $9 \pm 2 \mathrm{~ms}$ after uncaging $(n=24$ trials at 8 locations in 4 cells; $p<0.001)$, suggesting that the latent period is terminated in part by calcium feedback on the $\mathrm{IP}_{3}$ receptor. The initial rate of calcium release increased by $65 \pm$ $15 \%$ (Fig. $3 D$ ) [slope of linear sum $=1.7 \pm 0.2\left(\% \Delta F / F_{0}\right) / \mathrm{ms}$, slope of coincidence response $=2.8 \pm 0.3\left(\% \Delta F / F_{0}\right) / \mathrm{ms}, n=$ 24]. These measurements suggest that calcium accelerates steps in receptor activation that occur after $\mathrm{IP}_{3}$ binding.

One possible alternate means for presentation of $\mathrm{IP}_{3}$ to boost the size of a CF-evoked calcium signal would be by regional alteration of the membrane potential. If $\mathrm{IP}_{3}$-evoked calcium release were sufficient to hyperpolarize the dendrite by activating calcium-activated potassium conductance (Canepari and Ogden, 
A

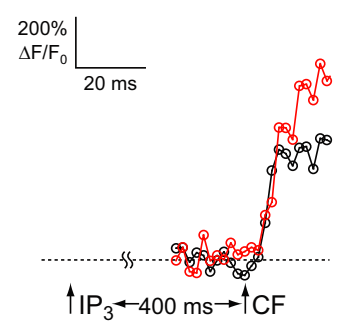

B

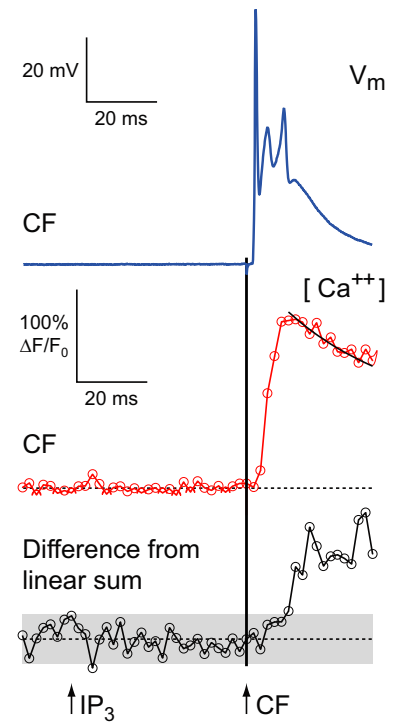

C

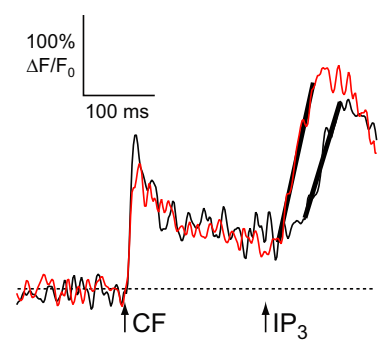

D

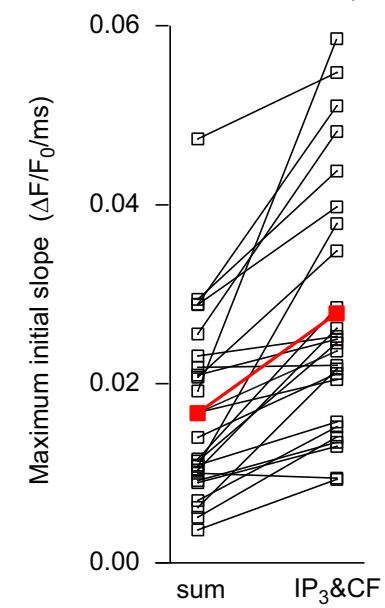

Figure 3. Kinetics of onset of calcium-dependent coincidence detection. $\boldsymbol{A}$, Calcium transient in response to coincident activation (red trace) diverges from the linear sum of signals (black trace) starting $\sim 10 \mathrm{~ms}$ after CF activation. Traces from Figure $1 C$. $\boldsymbol{B}$, CF-evoked action potential (top), calcium signal (middle, red), and difference between coincidence and linear sum of $C F$ and $I P_{3}$ responses (bottom, black). The difference signal averaged across experiments passes outside the \pm 2 SD range (gray band) $10-12$ ms after the CF stimulus. C, Speeding of calcium release kinetics induced when a CF spike precedes uncaging (red trace, coincidence signal; black trace, linear sum of individual signals). The gray lines show linear fits of the initial rate of rise of calcium. $\boldsymbol{D}$, Increase of the rate of the $\mathrm{IP}_{3}$-induced calcium release by $C F$ spike. The red line corresponds to the example from $C$.

response enhancement followed that of the size of calcium release after $\mathrm{IP}_{3}$ uncaging nearly perfectly $(r=+0.96)$ (Fig. $4 B$ ). Second, we performed coincidence detection experiments with increased extracellular potassium while injecting current to drive voltage to the reversal potential, -70 $\mathrm{mV}$. Under these conditions, supralinearity still occurred in spiny dendrites $(C=$ $0.47 \pm 0.10, p<0.05, n=11$ trials at 4 locations in 2 cells; $\mathrm{IP}_{3}$-to-CF interval of $200 \mathrm{~ms}$ ) even though the CF-alone signal was longer in duration (data not shown). Third, as stated previously, in both spines and shafts presentation of CF before $\mathrm{IP}_{3}$ led to supralinearity (Fig. $2 \mathrm{~B}, \mathrm{C}$ ). These three lines of experimental evidence argue that $\mathrm{IP}_{3}$ receptor-mediated coincidence detection does not require hyperpolarization.

Another putative contributor to coincidence detection is saturation of binding calcium buffer. Saturation of millisecondspeed binding sites by either PF or CF input-evoked calcium entry or release could create a situation in which activation of both inputs at once would generate a supralinear enhancement in free calcium (Maeda et al., 1999). Such enhancement is very unlikely with the endogenous calcium-binding capacity of cells, which does not saturate at micromolar concentrations of calcium (Neher, 1998), or with parvalbumin, whose binding equilibrium is very slow, taking place in $\sim 1 \mathrm{~s}$ (Eberhard and Erne, 1994; Lee et al., 2000). The cerebellar buffer protein that is both fast and saturable is calbindin-28k, which can bind calcium with a fast on-rate and has submi-

2006), an increased driving force would result, leading to greater $\mathrm{CF}$-evoked calcium entry. $\mathrm{IP}_{3}$-alone calcium signals were restricted largely to spines and smaller in amplitude than the amount of CF-evoked calcium entry, indicating that any hyperpolarization is likely to be small. Nonetheless, hyperpolarizationbased boosting is possible, and leads to three specific predictions. First, boosting would be spatially widespread because the voltage change would spread electrotonically beyond the site of calcium release. Second, boosting would not occur when voltage is already near the reversal potential for potassium, and it would not occur in the primary dendrite because of its proximity to the cell body. Third, boosting should occur only when $\mathrm{IP}_{3}$-dependent calcium release precedes the CF stimulus.

We tested these three predictions. First, we examined CFevoked calcium signals in dendritic shafts after $\mathrm{IP}_{3}$ was uncaged up to $15 \mu \mathrm{m}$ away (Fig. $4 \mathrm{~A}$ ), far from the site of calcium release but well within the electrotonic range of dendritic voltage spread (Roth and Häusser, 2001). In these cases, the CF-evoked signal was not enhanced by distant $\mathrm{IP}_{3}$ uncaging $(C=0.07 \pm 0.06, n=$ 28 trials in 9 locations in 2 cells, 7-9 $\mu \mathrm{m}$ away from uncaging locations, $\mathrm{IP}_{3}$-to-CF interval of $200 \mathrm{~ms}$; not significantly different from zero, $p=0.34$ ), in contrast to coincidence signals at uncaging locations in the same recordings $(C=0.75 \pm 0.13, n=26$ trials at 9 locations in 2 cells). The spatial profile of CF-evoked cromolar affinity (Nägerl et al., 2000) and is abundant in Purkinje cells (Kosaka et al., 1993). Calbindin-28k can also shape the amplitude of $\mathrm{IP}_{3}$-dependent signals in Purkinje cells (Sarkisov et al., 2007). In calbindin-28k knock-out mice, coincidence-evoked dendritic calcium transients were still supralinear (Fig. 4C) $(C=$ $0.73 \pm 0.18, p<0.01, n=14$ trials at 7 locations in 4 cells; $\mathrm{IP}_{3}$-to-CF interval of 50-400 ms), consistent with an earlier report that associative cerebellar LTD is not impaired in calbindin knock-out animals (Barski et al., 2003) and indicating that fast binding by calbindin does not play a strong role in orderdependent coincidence detection.

Together these tests for the involvement of various pathways in generating supralinearity (summarized in Fig. 4D) are all consistent with a mechanism for coincidence detection in which calcium-dependent enhancement of $\mathrm{IP}_{3}$ receptor activity occurs, driven by fast calcium-dependent activation and inactivation processes (Finch et al., 1991). However, in addition to calcium's positive effect, calcium elevations of $\sim 1-10 \mu \mathrm{M}$ for $200-1000 \mathrm{~ms}$ have been previously reported to inhibit $\mathrm{IP}_{3}$-mediated calcium release (Finch et al., 1991; Khodakhah and Ogden, 1995; Michikawa et al., 1999). The dual action of calcium raises the possibility that calcium could have both positive and negative effects on calcium release. We therefore measured coincidencedependent calcium release after giving multiple CF stimuli as a 
means of increasing the amount of calcium entry (Fig. 5A). The amount of enhancement (coincidence minus CF-alone response) was $1.68 \pm 0.28$ times larger for three CF stimuli in dendrites, and $1.61 \pm$ 0.15 times larger for three CF stimuli in spines, than by pairing with one CF stimulus (Fig. $5 B$ ). In all cases, the effect of multiple CF stimuli on $\mathrm{IP}_{3}$-mediated calcium release was a positive enhancement, indicating that the negative effects of calcium do not make a dominant contribution even when CFs fire in bursts.

If calcium release is enhanced by fast calcium binding to the $\mathrm{IP}_{3}$ receptor, then the timing window for CF-before- $\mathrm{IP}_{3} \mathrm{CO}-$ incidence detection might be determined by the time course of CF-evoked calcium elevation. We compared the coincidence index $C$ (Fig. 2C,D) measured at different values of $\Delta t$ with the calcium concentration occurring at the same interval after CF activation in the average $\mathrm{CF}$-evoked transient (Fig. 5C,D, insets). A robust correlation between calcium release enhancement and the respective calcium concentration was observed both in spine (Fig. 5C) and dendrite (Fig. 5D) data. The amount of supralinearity $C$ increased approximately linearly with the CF-triggered calcium elevation in both spines $(r=$ $+0.92, p<0.001)$ and in dendrites $(r=$ $+0.93, p<0.001)$.

Conversely, to account for the $\mathrm{IP}_{3}$ before-CF timing window we examined candidate mechanisms for terminating $\mathrm{IP}_{3}$ receptor activation by performing pairedpulse uncaging experiments (Fig. $6 A$ ). The response to a pulse of $\mathrm{IP}_{3}$ in a primary dendrite was strongly enhanced by a preceding pulse, even when the two pulses were separated by as long as $400 \mathrm{~ms}$ (Fig. 6A), a time interval that is substantially longer than the estimated diffusion time of second messengers out of the uncaging focal volume (Allbritton et al., 1992) or through spine necks (Svoboda et al., 1996). The en-

hancing effect of the first $\mathrm{IP}_{3}$ pulse declined with interpulse interval (Fig. 6B). These experiments support the possibility that $\mathrm{IP}_{3}$ receptors can be activated for hundreds of milliseconds after presentation of agonist. However, this interpretation is ambiguous because photolysis of double-caged $\mathrm{IP}_{3}$ generates a partial photoproduct, single-caged $\mathrm{IP}_{3}$, that can be restricted to near the uncaging site. Single-caged $\mathrm{IP}_{3}$ itself could increase the effectiveness of a light pulse or, conversely, act as an antagonist to calcium release (Sarkisov et al., 2007). We therefore turned to singlecaged PIP $_{2}$, an $\mathrm{IP}_{3}$ analog that triggers dendritic calcium release (Sarkisov et al., 2007) and is poorly hydrolyzable (Bird et al., 1992). Paired-pulse enhancement using gPIP $_{2}$ was greatest at the shortest intervals and dropped to half-maximal values at an interval of $400 \pm 25 \mathrm{~ms}$ (Fig. 6C). This half-maximal time interval was similar to the binding dissociation time of $\mathrm{IP}_{3}$ from its receptor measured in vitro (Hannaert-Merah et al., 1994) and esticonditions.

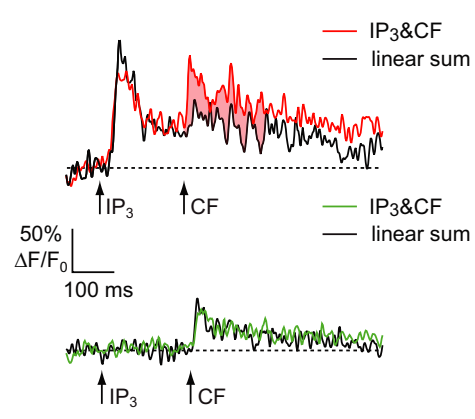

C

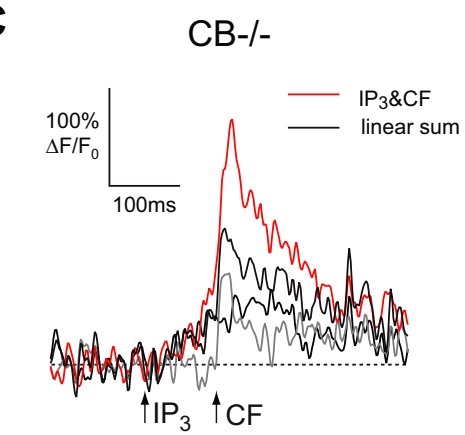

Figure 4. Tests of alternate mechanisms for coincidence detection. $\boldsymbol{A}$, Distance dependence of calcium signal enhancement. An Black line shows scaled calcium response to $\mathrm{IP}_{3}$ uncaging alone. Shading shows $95 \%$ confidence intervals. $C$, Example of enhanced calcium transients in a calbindin knock-out mouse. D, Summary of the size of the supralinear component $C$ under various

mated from measurements using stopped-flow calcium release measurements (Meyer et al., 1990). Together, these experiments suggest that $\mathrm{IP}_{3}$ receptors can integrate recent $\mathrm{IP}_{3}$ availability to set a time window for $\mathrm{IP}_{3}$-before-CF coincidence, and that degradation does not play a limiting role in setting the timing window.

To test the degree to which agonist activation of receptors could account for the shape of the timing window of $\mathrm{IP}_{3}$ before-CF coincidence, the degree of enhancement observed in paired-pulse $\mathrm{gPIP}_{2}$ uncaging experiments was plotted against the supralinearity index for $\mathrm{IP}_{3}$-before-CF for the same timing interval (Fig. 6D). For spine data with intervals $>85 \mathrm{~ms}$ (Fig. $6 D$, black symbols), the resulting relationship was linear $(r=0.96$, $p<0.001$ ). A deviation for intervals $<85 \mathrm{~ms}$ (Fig. 6D) (gray symbols) was observed, reflecting the fact that the largest coincidence signals were observed for timings somewhat offset from 
A

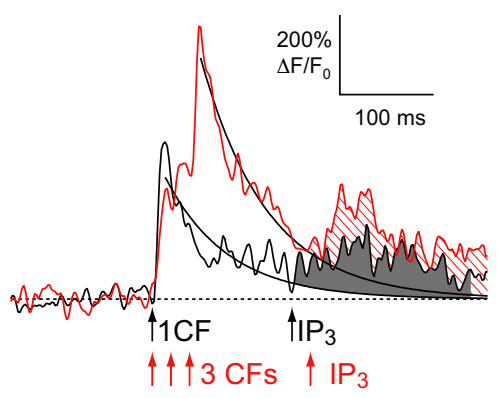

C

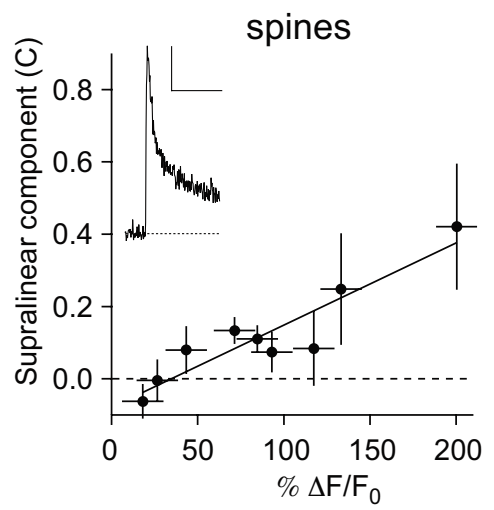

B

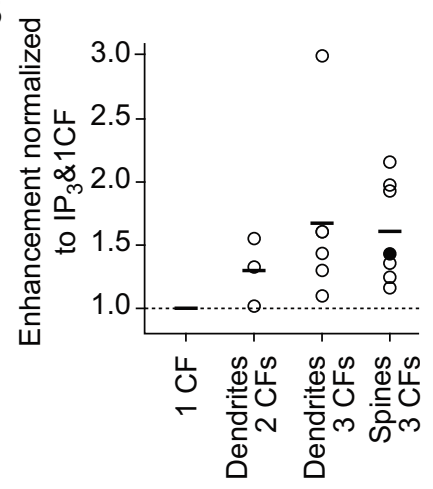

D

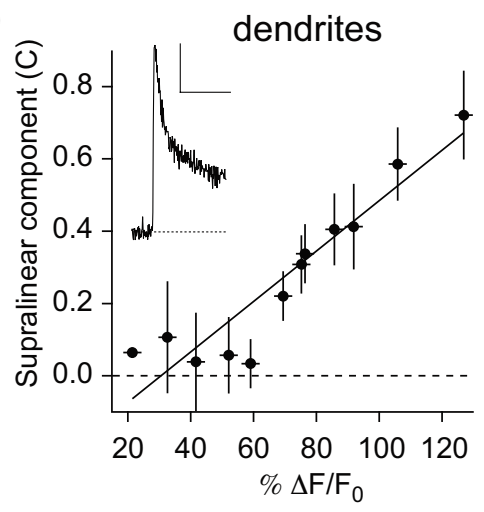

Figure 5. Prediction of supralinearity from calcium dynamics. $A$, Enhancement of calcium release increases with the number of CF stimuli. $\boldsymbol{B}$, Dependence of enhancement of calcium release on the number of CF spikes. The filled symbol corresponds to the example shown in $\boldsymbol{A}$. $\boldsymbol{C}$, Supralinear component $\left(\right.$ for the full range of time intervals of $C F$ preceding $\mathbb{I}_{3}$ (data from Fig. $2 C, D$ ) plotted against the size of the calcium transient in spines measured at the same time interval after delivering a CF stimulus. Inset, Average of all CF-evoked spine transients. Calibration: $100 \% \Delta F / F_{0}, 200 \mathrm{~ms}$. D, Supralinear component C plotted against the size of the calcium transient in dendrites at the corresponding time interval. Inset, Average of all CF-evoked dendritic transients. Calibration: $50 \% \Delta F / F_{0}, 200 \mathrm{~ms}$.

zero (Fig. 2C). Thus, at short timing intervals, supralinearity is smaller than would be expected from paired-pulse experiments. Reduced supralinearity for short timing intervals might be expected if multiple $\mathrm{IP}_{3}$ molecules must bind (Meyer et al., 1990; Finch et al., 1991) before calcium is able to coactivate the receptor.

\section{Discussion}

We have shown that maximal activation of calcium release in cerebellar Purkinje neurons by $\mathrm{IP}_{3}$ depends on the timing with which the $\mathrm{IP}_{3}$ receptor's coagonist, calcium, is presented. Maximal calcium release occurs when $\mathrm{IP}_{3}$ and calcium are presented not only simultaneously, but also over an asymmetric timing window in which effective coincidence is possible when $\mathrm{IP}_{3}$ is presented between $500 \mathrm{~ms}$ before and $100 \mathrm{~ms}$ after calcium entry.

The dynamics of calcium and $\mathrm{IP}_{3}$ action on the $\mathrm{IP}_{3}$ receptor can be summarized in a simplified model (Fig. 7) in which $\mathrm{IP}_{3}$ receptor channel opening is enhanced after formation of a complex with both $\mathrm{IP}_{3}$ and calcium. The timing conditions under which coincidence detection occurs are then defined by calcium clearance mechanisms, which shape the CF-evoked calcium transient, and by an intrinsic receptor property, the lifetime of $\mathrm{IP}_{3}$ binding.

The canonical synaptic detector of event order has been the NMDA receptor (Abbott and Nelson, 2000), which binds glutamate for longer than the time course of action potential-induced depolarization, a coactivator of the receptor. The $\mathrm{IP}_{3}$ receptor

provides a second mechanism for order detection (Marchant and Taylor, 1997). Order-dependent activation of $\mathrm{IP}_{3}$ receptors can account for order dependence in neurons that lack NMDA receptors, such as Purkinje cells. To form an analogy with NMDA receptors, at $\mathrm{IP}_{3}$ receptors the role of glutamate is taken by $\mathrm{IP}_{3}$; the role of depolarization and magnesium unblock is taken by calcium entry.

Previously we reported that calcium release in Purkinje cells triggered by PF activation is preferentially enhanced when $\mathrm{PF}$ activity is delivered before CF activity but not after (Wang et al., 2000). One detailed model of our data (Doi et al., 2005) found that several parameters might be able to shape the timing window, including delays in PF-triggered $\mathrm{IP}_{3}$ synthesis and degradation of $\mathrm{IP}_{3}$. The lifetime of $\mathrm{IP}_{3}$ elevation has also been suggested to set a time window for coincidence detection in CA1 pyramidal neurons (Nakamura et al., 1999). By bypassing $\mathrm{IP}_{3}$ synthesis, we now show that the integrative properties of $\mathrm{IP}_{3}$ receptors are sufficient to achieve order dependence without calling on a role for $\mathrm{IP}_{3}$ metabolism. Our optimal timing is slightly offset from zero (Fig. 2C,D), indicating that additional complexity in $\mathrm{IP}_{3}$ receptor dynamics such as sequential binding of multiple $\mathrm{IP}_{3}$ molecules (Meyer et al., 1990; Marchant and Taylor, 1997) may be necessary for receptor activation. Peak fluorescence changes in response to $\mathrm{IP}_{3}$ uncaging followed by CF activation correspond to calcium changes of up to $\sim 2 \mu \mathrm{M}$, consistent with previously reported spine signals (Wang et al., 2000) and based on recent experiments using caged calcium, high enough to be able to drive LTD (Tanaka et al., 2007). Asymmetric timing dependence of PF-PC LTD can thus be accounted for by the intrinsic dynamics of the $\mathrm{IP}_{3}$ receptor.

Our analysis provides a useful lesson in the use of saturating indicator dyes. Although the true supralinearity of calcium release was approximately twice as large as that calculated in fluorescence units (Fig. 2C) (supplemental Fig. 1, available at www. jneurosci.org), the shape of the fitted timing window was unchanged by conversion to calcium units. The robustness of result is not unexpected: in numerical calculations, assuming a supralinearity in $\Delta F / F_{0}$ of 2 , transformation into fluorescence of a Gaussian distribution with a peak $[\mathrm{Ca}]=K_{\mathrm{D}}$ leads to at most an $\sim 20 \%$ overestimate of the half-width. Thus even with a moderate degree of indicator saturation, timing dependence can be estimated without the intervening step of a calibration procedure.

In situ measurement of the sensitivity of $\mathrm{IP}_{3}$ receptormediated coincidence detection to timing shifts of as little as tens of milliseconds was made possible by the use of caged $\mathrm{IP}_{3}$, in which cages are photolyzed with a single-cage dark reaction time of $\sim 7$ ms (Walker et al., 1987), and double-uncaging events, which generate $\mathrm{IP}_{3}$, take place approximately $\sqrt{2}$-fold more slowly $(\sim 10 \mathrm{~ms})$. These timescales are shorter than both the duration of parallel fiber firing bursts (multiple tens of milliseconds) and the kinetics of G-protein-coupled receptor enzyme 
activation. Thus, our uncaging experiments probe $\mathrm{IP}_{3}$ receptor dynamics on physiologically relevant time scales.

A second technical advantage of the present experiments is the localization of uncaging to fine dendrites and spines. Biochemical fast perfusion experiments (Finch et al., 1991) indicate that a key determinant of whether calcium activates or inactivates the $\mathrm{IP}_{3}$ receptor is how quickly calcium is presented to the receptor. Previous work in brain slices (Khodakhah and Ogden, 1995) reported only negative effects of calcium on $\mathrm{IP}_{3}$ receptor activity, but these experiments lacked spatial specificity and elevated calcium only on slower time scales. Because of surface-to-volume considerations, action potentials in large structures such as somata lead to smaller and more prolonged calcium transients than in fine dendrites and spines, making fast regulation difficult to probe. Caution is needed in extrapolating the properties of spine calcium release from experiments done on the scale of whole cells and arbors.

Spines have been suggested to act as biochemical compartments (Koch and Zador, 1993; Svoboda et al., 1996). We recently found that focal photolysis of double-caged $\mathrm{IP}_{3}$ can generate calcium release that is confined to spines; double caging is necessary because single-caged $\mathrm{IP}_{3}$ is an antagonist of calcium release (Sarkisov et al., 2007). In those experiments, the poorly hydrolyzable analog gPIP $_{2}$ led to reduced spine localization, indicating that $\mathrm{IP}_{3}$ degradation plays a major role in confining $\mathrm{IP}_{3}$ signals. One numerical model of $\mathrm{IP}_{3}$ receptor-based signaling in Purkinje cell dendrites (Hernjak et al., 2005) has suggested that limits on diffusion by narrow spine necks could be necessary for coincidence detection. We found that the timing-dependent properties of coincidence detection are similar in spines and shafts and that coincidence detection was possible even in the primary dendrite, indicating that coincidence detection is not affected by the local diffusional environment. In another study done in hippocampal pyramidal neurons (Nakamura et al., 1999), it was suggested that $\mathrm{IP}_{3}$ degradation could limit the interval during which action potentials could enhance calcium release. However, our results with a poorly hydrolyzable analog, $\mathrm{gPIP}_{2}$, argue that in Purkinje cells $\mathrm{IP}_{3}$ degradation is not limiting. Together, our studies to date suggest that spine specificity of Purkinje cell calcium release requires a combination of restricted diffusion and rapid $\mathrm{IP}_{3}$ degradation, whereas temporal integration with CF-evoked calcium entry depends largely on intrinsic $\mathrm{IP}_{3}$ receptor dynamics.

The present work complements previous studies of two forms of order-dependent coincidence detection. In addition to calcium release, another well characterized form of coincidence detection based on calcium is nonlinear amplification by voltagegated calcium channels (Wang et al., 2000; Brenowitz and Regehr, 2005). Coincidence detection of PF and CF input in whole dendritic branchlets occurs when PFs are activated with
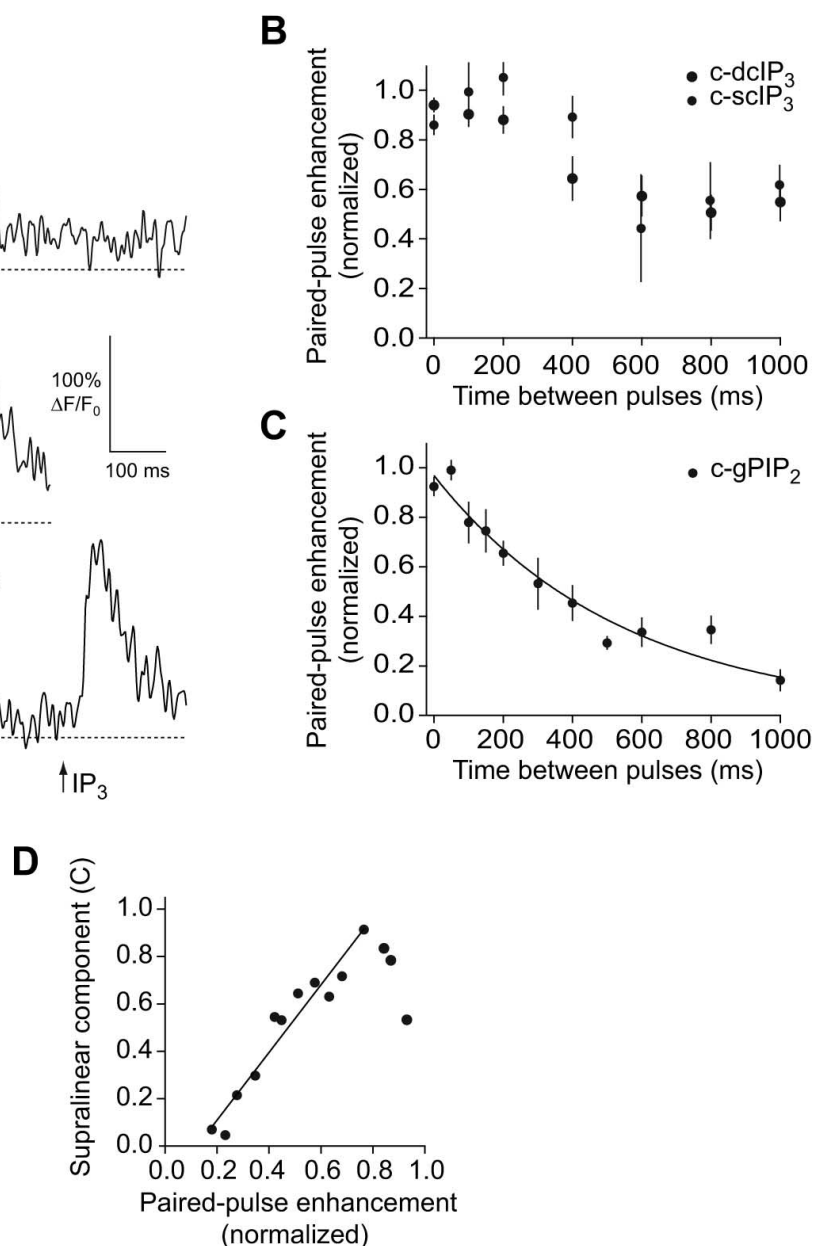

(normalized)

Figure 6. Prediction of supralinearity from $\mathrm{IP}_{3}$ receptor activation dynamics. $A$, Enhancement of calcium release in response to singleSupralinear component $\left(\right.$ for each $\mathrm{IP}_{3}$-preceding- $\mathrm{C}$ time interval (data from Fig. $2 c$ ) plotted against paired-pulse enhancement for $\mathrm{PPIP}$ with the pulses separated by the same time interval. The amount of paired-pulse enhancement i interpolated from a fit to the caged $\mathrm{PIP}_{2}$ data in $C$. The gray symbols indicate data points for intervals of $\mathrm{IP}_{3}$ preceding $\mathrm{CF}$ by 26,65 , and $82 \mathrm{~ms}$.

sufficient density, followed by CF activation. Voltage-dependent amplification is also largest when PF activation occurs before CF activity (Brenowitz and Regehr, 2005), suggesting that order detection by calcium signals in Purkinje cells may be robust in the sense that both $\mathrm{IP}_{3}$-based and voltage-based mechanisms favor the same order of PF and CF activation.

Order dependence of calcium signaling and LTD induction may be a necessary component of the temporal dependence of sensory conditioning. Order-dependent coincidence detection can account in part for the temporal dependence of several forms of sensory learning thought to involve the cerebellum (Mauk et al., 1998). In eyeblink conditioning, a conditional stimulus such as a tone has been suggested to trigger PF activity. For conditioning to occur, the tone must precede the airpuff, thought to be encoded by CF activity, by at least $80 \mathrm{~ms}$ (Gormezano et al., 1983). A similar timing dependence is also suggested in studies of gain adaptation of the vestibulo-ocular reflex (Raymond and Lisberger, 1998). Delayed timing dependence is a proposed feature of an "eligibility trace" (Sutton and Barto, 1981), a marker that is formed by a conditional stimulus such as a tone and that tags activated structures to undergo plasticity if they then receive an 


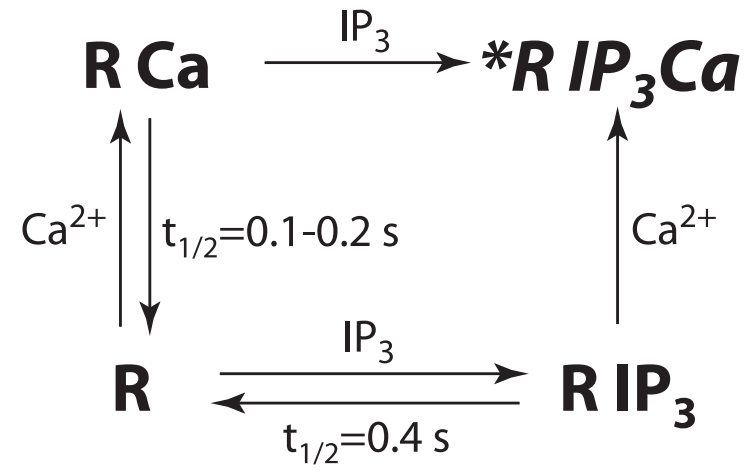

Figure 7. Model of order-dependent coincidence detection. Enhanced calcium release through the $\mathbb{I P}_{3}$ receptor occurs when both $\mathbb{P}_{3}$ and calcium are bound to the receptor. If the $C F$ stimulus precedes $\mathbb{P}_{3}$ production, enhancement requires $\mathbb{I}_{3}$ to bind to the receptor during the CF stimulus-evoked calcium transient, which lasts $0.1-0.2 \mathrm{~s}$. IP $\mathrm{P}_{3}$ enhances the effect of a $\mathrm{CF}$ stimulus that arrives within $\sim 0.4 \mathrm{~s}$, the lifetime of $\mathbb{I}_{3}$ unbinding from the receptor.

instruction in the form of an unconditional stimulus, such as an airpuff. In this conceptual framework, the accumulation and decay of receptor-bound $\mathrm{IP}_{3}$ may constitute an eligibility trace.

A remaining question is what shapes the overall learning rule's dependence on stimulus pattern and intensity. The induction of PF-LTD may require, in addition to $\mathrm{IP}_{3}$ and calcium entry, convergence with other second messenger systems. Other putative participants in signal convergence in PF- and CF-activated biochemical pathways (Ito, 2002) are PKC, nitric oxide/cGMP/endocannabinoid pathways (Lev-Ram et al., 1997; Rancz and Häusser, 2006), and voltage-gated calcium channels (Wang et al., 2000; Brenowitz and Regehr, 2005), which play roles in triggering bidirectional synaptic plasticity-not only LTD, but also longterm potentiation (Coesmans et al., 2004). Thus the timing dependence of PF-PC synaptic plasticity may also be affected by steps both upstream and downstream of $\mathrm{IP}_{3}$ formation and action on receptors. The multiple pathways implicated in LTD induction may account for the variability in past reports of the timing dependence of PF-PC LTD induction (Ekerot and Kano, 1989; Karachot et al., 1994; Chen and Thompson, 1995; Wang et al., 2000), including reversed timing dependence (Ekerot and Kano, 1989; Karachot et al., 1994) and dependence on the number of pairings (Chen and Thompson, 1995). Convergence involving multiple signaling molecules would further shape the synaptic learning rules by which PF and CF activity patterns are mapped into long-term storage of information in the cerebellum.

\section{References}

Abbott LF, Nelson SB (2000) Synaptic plasticity: taming the beast. Nat Neurosci 3:1178-1183.

Allbritton NL, Meyer T, Stryer L (1992) Range of messenger action of calcium ion and inositol 1,4,5-trisphosphate. Science 258:1812-1815.

Barski JJ, Hartmann J, Rose CR, Hoebeek F, Morl K, Noll-Hussong M, De Zeeuw CI, Konnerth A, Meyer M (2003) Calbindin in cerebellar Purkinje cells is a critical determinant of the precision of motor coordination. J Neurosci 23:3469-3477.

Bear MF, Linden DJ (2001) The mechanisms and meaning of long-term synaptic depression in the mammalian brain. In: Synapses (Cowan WM, Südhof TC, Stevens, CF, eds), pp 455-517. Baltimore: Johns Hopkins.

Berridge MJ (1993) Cell signalling. A tale of two messengers. Nature 365:388-389.

Bezprozvanny I, Watras J, Ehrlich BE (1991) Bell-shaped calcium-response curves of $\operatorname{Ins}(1,4,5) \mathrm{P}_{3^{-}}$and calcium-gated channels from endoplasmic reticulum of cerebellum. Nature 351:751-754.

Bird GS, Obie JF, Putney Jr JW (1992) Sustained $\mathrm{Ca}^{2+}$ signaling in mouse lacrimal acinar cells due to photolysis of "caged" glycerophosphorylmyo-inositol 4,5-bisphosphate. J Biol Chem 267:17722-17725.
Brenowitz SD, Regehr WG (2005) Associative short-term synaptic plasticity mediated by endocannabinoids. Neuron 45:419-431.

Canepari M, Ogden D (2006) Kinetic, pharmacological and activitydependent separation of two $\mathrm{Ca}^{2+}$ signalling pathways mediated by type 1 metabotropic glutamate receptors in rat Purkinje neurones. J Physiol (Lond) 573:65-82.

Chen C, Thompson RF (1995) Temporal specificity of long-term depression in parallel fiber-Purkinje synapses in rat cerebellar slice. Learn Mem 2:185-198.

Coesmans M, Weber JT, De Zeeuw CI, Hansel C (2004) Bidirectional parallel fiber plasticity in the cerebellum under climbing fiber control. Neuron 44:691-700.

Doi T, Kuroda S, Michikawa T, Kawato M (2005) Inositol 1,4,5trisphosphate-dependent $\mathrm{Ca}^{2+}$ threshold dynamics detect spike timing in cerebellar Purkinje cells. J Neurosci 25:950-961.

Dzubay JA, Otis TS (2002) Climbing fiber activation of metabotropic glutamate receptors on cerebellar Purkinje neurons. Neuron 36:1159-1167.

Eberhard M, Erne P (1994) Calcium and magnesium binding to rat parvalbumin. Eur J Biochem 222:21-26.

Ekerot CF, Kano M (1989) Stimulation parameters influencing climbing fibre induced long-term depression of parallel fibre synapses. Neurosci Res 6:264-268.

Finch EA, Turner TJ, Goldin SM (1991) Calcium as a coagonist of inositol 1,4,5-trisphosphate-induced calcium release. Science 252:443-446.

Furuichi T, Yoshikawa S, Miyawaki A, Wada K, Maeda N, Mikoshiba K (1989) Primary structure and functional expression of the inositol 1,4,5trisphosphate-binding protein P400. Nature 342:32-38.

Gormezano I, Kehoe EJ, Marshall BS (1983) 20 years of classicalconditioning research with the rabbit. Prog Psychobiol Physiol Psychol 10:197-275.

Grobler JA, Hurley JH (1998) Catalysis by phospholipase C delta1 requires that $\mathrm{Ca}^{2+}$ bind to the catalytic domain, but not the $\mathrm{C} 2$ domain. Biochemistry 37:5020-5028.

Hannaert-Merah Z, Coquil JF, Combettes L, Claret M, Mauger JP, Champeil P (1994) Rapid kinetics of myo-inositol trisphosphate binding and dissociation in cerebellar microsomes. J Biol Chem 269:29642-29649.

Hernjak N, Slepchenko BM, Fernald K, Fink CC, Fortin D, Moraru II, Watras J, Loew LM (2005) Modeling and analysis of calcium signaling events leading to long-term depression in cerebellar Purkinje cells. Biophys J 89:3790-3806.

Iino M (1990) Biphasic $\mathrm{Ca}^{2+}$ dependence of inositol 1,4,5-trisphosphateinduced Ca release in smooth muscle cells of the guinea pig taenia caeci. J Gen Physiol 95:1103-1122.

Inoue T, Kato K, Kohda K, Mikoshiba K (1998) Type 1 inositol 1,4,5trisphosphate receptor is required for induction of long-term depression in cerebellar Purkinje neurons. J Neurosci 18:5366-5373.

Ito M (2002) The molecular organization of cerebellar long-term depression. Nat Rev Neurosci 3:896-902.

Karachot L, Kado RT, Ito M (1994) Stimulus parameters for induction of long-term depression in in vitro rat Purkinje cells. Neurosci Res 21:161-168.

Khodakhah K, Armstrong CM (1997) Induction of long-term depression and rebound potentiation by inositol trisphosphate in cerebellar Purkinje neurons. Proc Natl Acad Sci USA 94:14009-14014.

Khodakhah K, Ogden D (1995) Fast activation and inactivation of inositol trisphosphate-evoked $\mathrm{Ca}^{2+}$ release in rat cerebellar Purkinje neurones. J Physiol (Lond) 487:343-358.

Koch C, Zador A (1993) The function of dendritic spines: devices subserving biochemical rather than electrical compartmentalization. J Neurosci 13:413-422.

Koekkoek SK, Hulscher HC, Dortland BR, Hensbroek RA, Elgersma Y, Ruigrok TJ, De Zeeuw CI (2003) Cerebellar LTD and learningdependent timing of conditioned eyelid responses. Science 301:1736-1739.

Kosaka T, Kosaka K, Nakayama T, Hunziker W, Heizmann CW (1993) Axons and axon terminals of cerebellar Purkinje cells and basket cells have higher levels of parvalbumin immunoreactivity than somata and dendrites-quantitative analysis by immunogold labeling. Exp Brain Res 93:483-491.

Lee S-H, Schwaller B, Neher E (2000) Kinetics of $\mathrm{Ca}^{2+}$ binding to parvalbumin in bovine chromaffin cells: implications for $\left[\mathrm{Ca}^{2+}\right]$ transients of neuronal dendrites. J Physiol (Lond) 525:419-432. 
Lev-Ram V, Jiang T, Wood J, Lawrence DS, Tsien RY (1997) Synergies and coincidence requirements between NO, cGMP, and $\mathrm{Ca}^{2+}$ in the induction of cerebellar long-term depression. Neuron 18:1025-1038.

Maeda H, Ellis-Davies GC, Ito K, Miyashita Y, Kasai H (1999) Supralinear $\mathrm{Ca}^{2+}$ signaling by cooperative and mobile $\mathrm{Ca}^{2+}$ buffering in Purkinje neurons. Neuron 24:989-1002.

Maravall M, Mainen ZF, Sabatini BL, Svoboda K (2000) Estimating intracellular calcium concentrations and buffering without wavelength ratioing. Biophys J 78:2655-2667.

Marcaggi P, Attwell D (2005) Endocannabinoid signaling depends on the spatial pattern of synapse activation. Nat Neurosci 8:776-781.

Marchant JS, Taylor CW (1997) Cooperative activation of $\mathrm{IP}_{3}$ receptors by sequential binding of $\mathrm{IP}_{3}$ and $\mathrm{Ca}^{2+}$ safeguards against spontaneous activity. Curr Biol 7:510-518.

Mauk MD, Garcia KS, Medina JF, Steele PM (1998) Does cerebellar LTD mediate motor learning? Toward a resolution without a smoking gun. Neuron 20:359-362.

Meyer T, Wensel T, Stryer L (1990) Kinetics of calcium channel opening by inositol 1,4,5-trisphosphate. Biochemistry 29:32-37.

Michikawa T, Hirota J, Kawano S, Hiraoka M, Yamada M, Furuichi T, Mikoshiba K (1999) Calmodulin mediates calcium-dependent inactivation of the cerebellar type 1 inositol 1,4,5-trisphosphate receptor. Neuron 23:799-808.

Miyakawa H, Lev-Ram V, Lasser-Ross N, Ross WN (1992) Calcium transients evoked by climbing fiber and parallel fiber synaptic inputs in guinea-pig cerebellar Purkinje neurons. J Neurophysiol 68:1178-1189.

Nägerl UV, Novo D, Mody I, Vergara JV (2000) Binding kinetics of calbindin- $\mathrm{D}_{28 \mathrm{k}}$ determined by flash photolysis of caged $\mathrm{Ca}^{2+}$. Biophys J 79:3009-3018.

Nakamura T, Barbara J-G, Nakamura K, Ross WN (1999) Synergistic release of $\mathrm{Ca}^{2+}$ from $\mathrm{IP}_{3}$-sensitive stores evoked by synaptic activation of mGluRs paired with backpropagating action potentials. Neuron 24:727-737.

Neher E (1998) Usefulness and limitations of linear approximations to the understanding of $\mathrm{Ca}^{++}$signals. Cell Calcium 24:345-357.

Rancz EA, Häusser M (2006) Dendritic calcium spikes are tunable triggers of cannabinoid release and short-term synaptic plasticity in cerebellar Purkinje neurons. J Neurosci 26:5428-5437.
Raymond JL, Lisberger SG (1998) Neural learning rules for the vestibuloocular reflex. J Neurosci 18:9112-9129.

Roth A, Häusser M (2001) Compartmental models of rat cerebellar Purkinje cells based on simultaneous somatic and dendritic patch-clamp recordings. J Physiol (Lond) 535:445-472.

Sakurai M (1990) Calcium is an intracellular mediator of the climbing fiber in induction of cerebellar long-term depression. Proc Natl Acad Sci USA 87:3383-3385.

Sarkisov DV, Wang SS-H (2006) Alignment and calibration of a focal neurotransmitter uncaging system. Nat Protocols 1:828.

Sarkisov DV, Gelber SE, Walker JW, Wang SS-H (2007) Synapse specificity of calcium release probed by chemical two-photon uncaging of inositol 1,4,5-trisphosphate. J Biol Chem 282:25517-25526.

Schreurs BG, Oh MM, Alkon DL (1996) Pairing-specific long-term depression of Purkinje cell excitatory postsynaptic potentials results from a classical conditioning procedure in the rabbit cerebellar slice. J Neurophysiol 75:1051-1060.

Sutton RS, Barto AG (1981) Toward a modern theory of adaptive networks: expectation and prediction. Psychol Rev 88:135-170.

Svoboda K, Tank DW, Denk W (1996) Direct measurement of coupling between dendritic spines and shafts. Science 272:716-719.

Takechi H, Eilers J, Konnerth A (1998) A new class of synaptic response involving calcium release in dendritic spines. Nature 396:757-760.

Tanaka K, Khiroug L, Santamaria F, Doi T, Ogasawara H, Ellis-Davies GC, Kawato M, Augustine GJ (2007) $\mathrm{Ca}^{2+}$ requirements for cerebellar longterm synaptic depression: role for a postsynaptic leaky integrator. Neuron 54:787-800.

Walker JW, Somlyo AV, Goldman YE, Somlyo AP, Trentham DR (1987) Kinetics of smooth and skeletal muscle activation by laser pulse photolysis of caged inositol 1,4,5-trisphosphate. Nature 327:249-252.

Wang SS-H, Denk W, Häusser M (2000) Coincidence detection in single dendritic spines mediated by calcium release. Nat Neurosci 3:1266-1273.

Woodruff ML, Sampath AP, Matthews HR, Krasnoperova NV, Lem J, Fain GL (2002) Measurement of cytoplasmic calcium concentration in the rods of wild-type and transducin knock-out mice. J Physiol (Lond) 542: 843-854. 